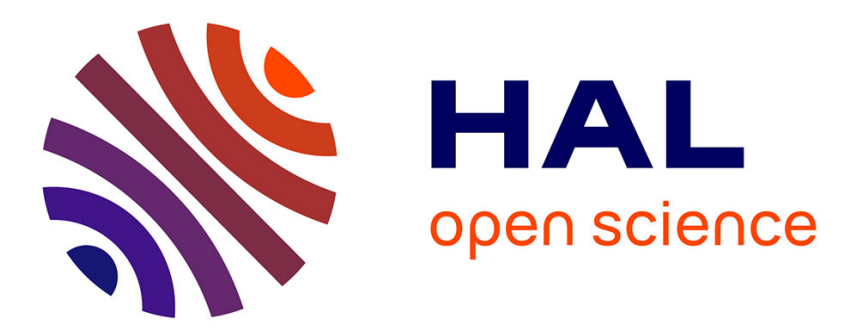

\title{
Effects of sliding on rolling contact fatigue of railway wheels
}

\author{
Amavi Langueh, Jean-François Brunel, Eric Charkaluk, Philippe Dufrenoy, \\ Jean-Bernard Tritsch, F. Demilly
}

\section{To cite this version:}

Amavi Langueh, Jean-François Brunel, Eric Charkaluk, Philippe Dufrenoy, Jean-Bernard Tritsch, et al.. Effects of sliding on rolling contact fatigue of railway wheels. Fatigue and Fracture of Engineering Materials and Structures, 2013, 36 (6), pp.515-525. 10.1111/ffe.12020 . hal-00863592

\section{HAL Id: hal-00863592 \\ https://hal.science/hal-00863592}

Submitted on 15 Jul 2021

HAL is a multi-disciplinary open access archive for the deposit and dissemination of scientific research documents, whether they are published or not. The documents may come from teaching and research institutions in France or abroad, or from public or private research centers.
L'archive ouverte pluridisciplinaire HAL, est destinée au dépôt et à la diffusion de documents scientifiques de niveau recherche, publiés ou non, émanant des établissements d'enseignement et de recherche français ou étrangers, des laboratoires publics ou privés. 


\title{
Effects of sliding on rolling contact fatigue of railway wheels
}

\author{
A. M. G. LANGUEH ${ }^{1,3,4}$, J.-F. BRUNeL ${ }^{1,3,4}$, E. CHARKALUK ${ }^{1,2,4}$, P. DUfRÉNOY $Y^{1,3,4}$, J.-B. TRITSCH ${ }^{1,3,4}$ \\ and F. DEMILLY ${ }^{5}$ \\ ${ }^{1}$ Univ Lille Nord de France, F-59000 Lille, France; ${ }^{2}$ ECLille, LML, F-59650 Villeneuve d'Ascq, France; ${ }^{3}$ USTL, LML, F-59650 Villeneuve d'Ascq, \\ France; ${ }^{4}$ CNRS, UMR 8107, F-59650 Villeneuve d'Ascq, France; ${ }^{5}$ GHH Valdunes, F-59125 Trith Saint Leger, France
}

A B STRACT This paper proposes a numerical approach based on a steady-state algorithm to predict the rolling contact fatigue crack initiation in railway wheels in practical conditions. This work suggests taking into account the cyclic hardening of the wheel's material and one of its originality is to conduct a complete numerical approach whatever the loading level. The main stages are the characterization and modelling of the material behaviour, the determination of the stress-strain fields using a numerical steady-state method and the application of a high cycle fatigue criterion. Computations were made with the Abaqus FE commercial software. Three cases are studied: rolling with or without sliding and skating. The numerical results give several types of mechanical responses: elastic or plastic shakedown. Otherwise, the results show that the location where the shear stress is maximal is not the same as where the risk of crack is the highest.

Keywords hardening; rolling contact fatigue; shakedown; steady-state algorithm.

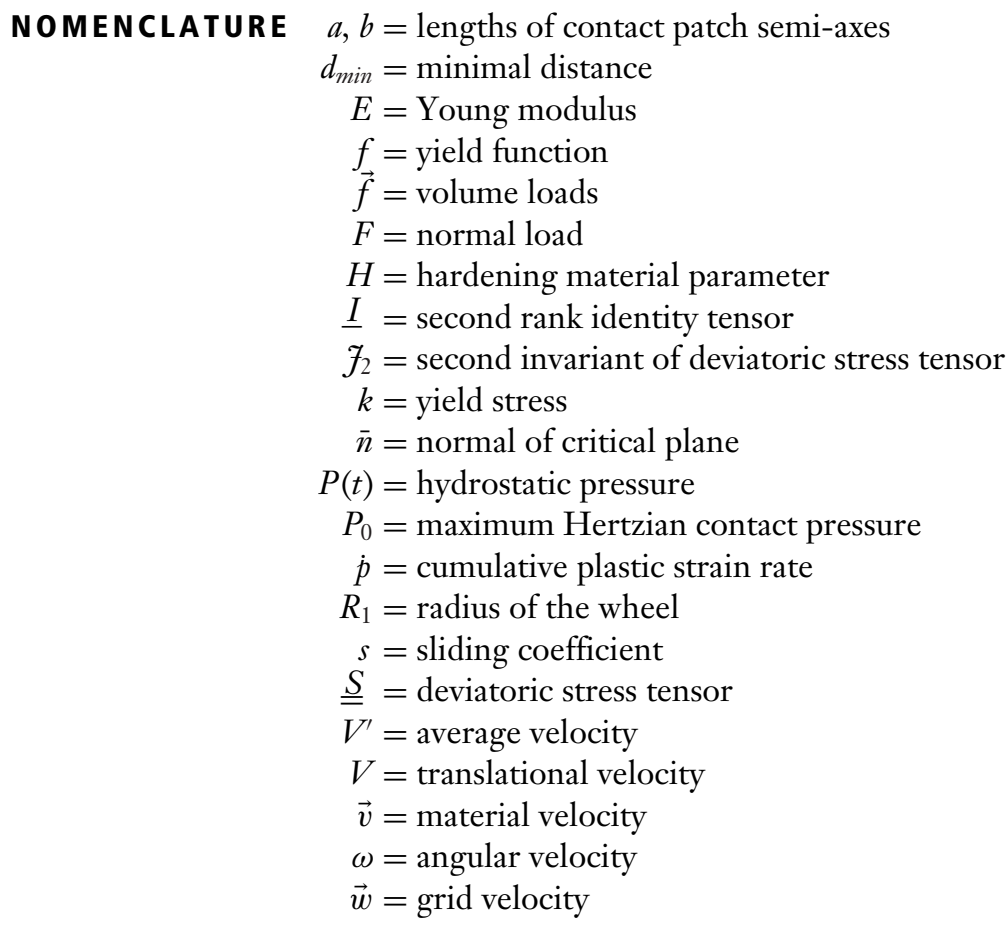




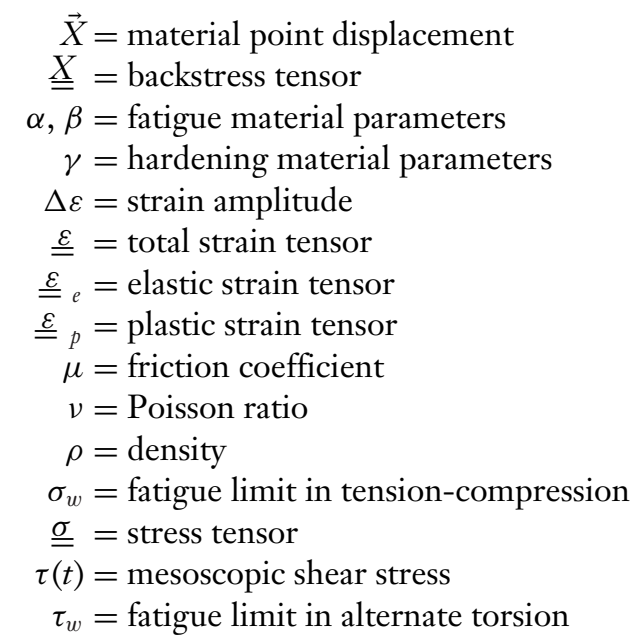

\section{INTRODUCTION}

Rolling contact fatigue (RCF) is a damage phenomenon that appears in rails and wheels due to overloading materials. Fatigue of railway wheels is an extremely important problem and becomes an important significant issue with respect to failure. Two processes govern RCF: crack initiation and crack propagation influenced by a large number of factors such as environmental conditions, rail and wheel profiles, track geometry and vehicle characteristics. ${ }^{1}$

The loads acting on the wheel lead to a multiaxial stress field in the wheel tread. The determination and the evaluation of this stress field is not an easy task because of the contact geometry between the wheel and the rail which is initially unknown. Johnson ${ }^{2}$ refers to a broad perspective of contact mechanics. The analysis is generally divided into two parts:

- Determination of the contact stress between the wheel and the rail: many researchers have taken an interest in wheel/rail contact to determine the shape and size of the contact patch, depending on the nature of the materials and loads, and have attempted to estimate the limits of adhesion and its values versus slip often based on Hertz elastic estimation. ${ }^{3}$ For cases where the contact geometry is not simple, the contact stress can be determined with iterative approaches. ${ }^{4}$ More consistent results can be obtained by performing an elastic-plastic analysis of the contact problem. Numerical models have to be employed, such as the FE method, with the introduction of numerical procedures to account for the contact determination (e.g. Lagrangian multiplier and/or penalty method).

- Evaluation of the stress field in the wheel resulting from the previously determined contact stress: the subsurface stress can be evaluated analytically if elastic conditions are assumed; the contact patch is generally replaced by a number of concentrated forces. ${ }^{5} \mathrm{FE}$ simulations can also be conducted. In these cases, elastic-plastic simulations can be performed and the full problem including the determination of both contact and sub-surface stress can be determined. ${ }^{6,7}$

To analyze the damage induced by the stress field, Johnson's approach is still widely used in railway engineering with the shakedown map (see Fig. 1), introduced in Refs $[8,9]$. The shakedown map shows the effect of the tangential traction and the load factor on the elastic limit and the shakedown limit, according to the von Mises yield

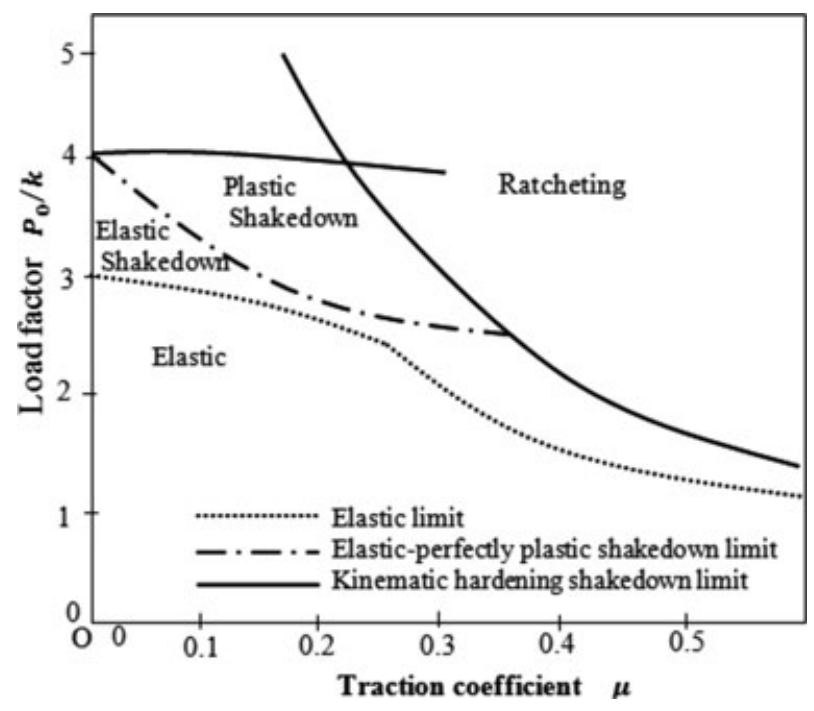

Fig. 1 Shakedown map from Johnson..$^{8,9}$ 
criterion. Several zones are identified in the shakedown map corresponding to the asymptotic responses under cyclic loadings: elastic behaviour, elastic shakedown, plastic shakedown and ratcheting. Note that the shakedown limit only considers perfectly plastic materials or kinematic hardening laws.

An extension of shakedown maps using a surface fatigue index has been proposed by Ekberg and Sotkovszki and is outlined in Ref. [10]. This index is a function of the friction, the geometry of the Hertz contact, the shear yield stress and the vertical load magnitude. The higher the index is, the higher the risk for surface fatigue is. In Refs $[11,12]$ these authors also evaluate the subsurface fatigue damage by taking into account the stress multiaxiality and then applying the Dang Van fatigue criterion. ${ }^{13}$ The calculated damage in the radial section of the wheel rim is summed at every point using the Palmgren-Miner rule applied to the equivalent Dang Van stresses. ${ }^{5}$

Some authors such as Bernasconi et al. ${ }^{14,15,16}$ have proposed multiaxial fatigue criteria suitable for different loadings, different materials or residual stresses generated by the railway wheel manufacturing process. They worked only on specimens and not directly on wheels. The residual stress used for the prediction of fatigue damage is determined experimentally by $\mathrm{X}$-ray diffraction. Another example is the study reported by Dang Van et al. ${ }^{17}$ providing numerical methods to predict fatigue phenomena applied to the rail.

Note that the Dang Van criterion is limited to elastic shakedown. For plastic shakedown, the Manson-Coffin criterion ${ }^{18,19}$ is often used to evaluate fatigue damage.

It should be underlined that these studies are highly based on simplified models, which do not take into account realistic mechanical cyclic constitutive laws for the materials considered and on simplified contact models. The aim of the present work is to develop a complete $3 \mathrm{D}$ numerical approach to predict RCF crack initiation in railway wheels taking into account the cyclic hardening of the materials and the sliding between the rail and the wheel. This approach is consistent whatever the loading level. In this paper, quite simple hardening law and high cycle fatigue (HCF) criterion are used which can easily be improved in the same framework.
Table 1 Chemical composition by volume (\%)

\begin{tabular}{llllllllll}
\hline$C$ & $S i$ & $M n$ & $P$ & $S$ & $C r$ & $M o$ & $N i$ & $V$ & $C r+M o+N i$ \\
\hline 0.52 & 0.40 & 0.80 & 0.20 & 0.30 & 0.30 & 0.80 & 0.30 & 0.80 & 0.50 \\
\hline
\end{tabular}

\section{MATERIAL CYCLIC MECHANICAL BEHAVIOUR}

R7T pearlite-ferrite steel (corresponding to European ER7) defined by the EN13262 standard ${ }^{20}$ is currently employed in wheel manufacturing. Its chemical composition is given in Table 1 .

\section{Characterization of specimens}

For the mechanical characterization of the material (cyclic behaviour and fatigue), specimens were taken from the rim of a railway wheel, $15 \mathrm{~mm}$ deep in the tangential direction, as shown in Fig. 2. The specimens' shape and dimensions are shown in Fig. 3.

Cyclic strain controlled tensile-compressive tests were first performed on specimens at different strain amplitudes $\Delta \varepsilon / 2$ from $0.2 \%$ to $1.2 \%$ at a constant strain rate of $6.6 * 10^{-4} \mathrm{~s}^{-1}$. The strain ratio is $R_{\varepsilon}=-1$. The loading description is shown in Fig. 4. The test was performed on a servo-hydraulic test system, equipped with a contact extensometer.

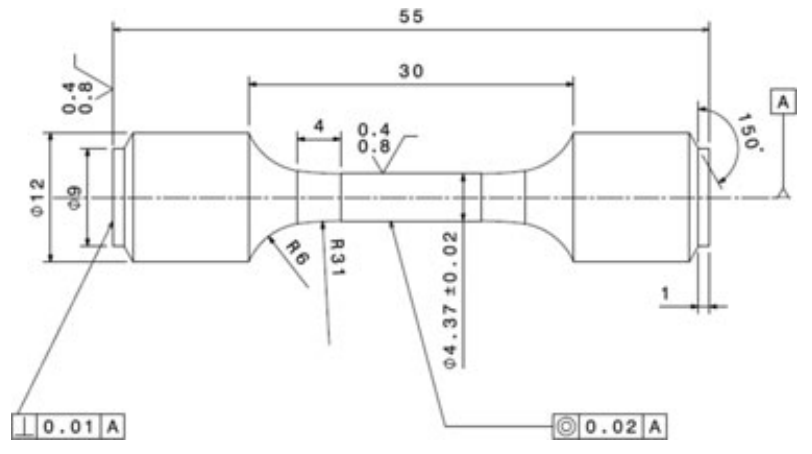

Fig. 3 Specimen shape and dimensions.

Fig. 2 Specimen extraction.
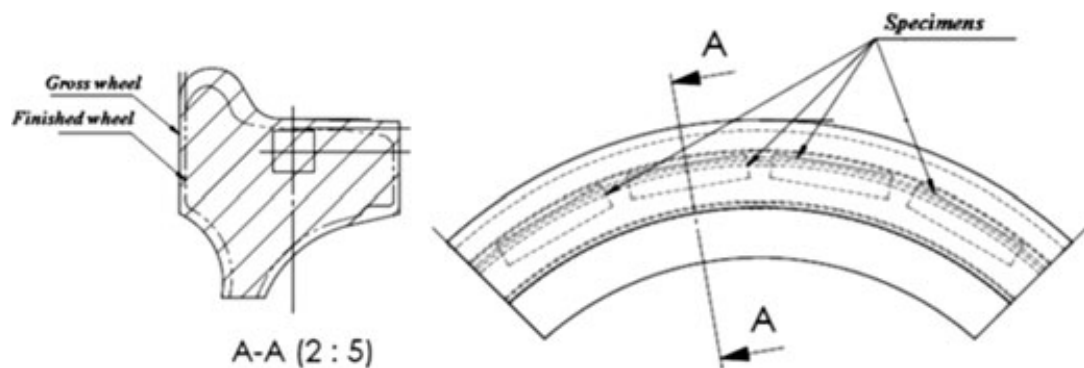


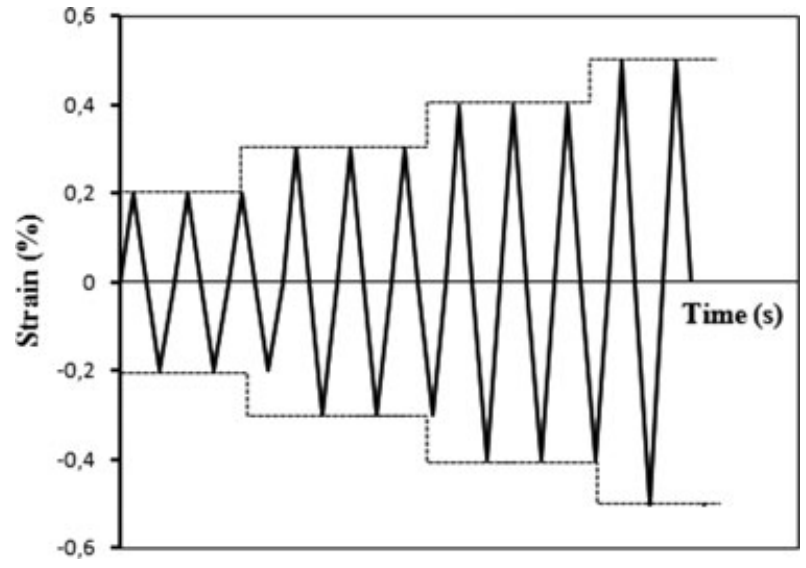

Fig. 4 Description of loading applied to specimens extracted from the wheel.

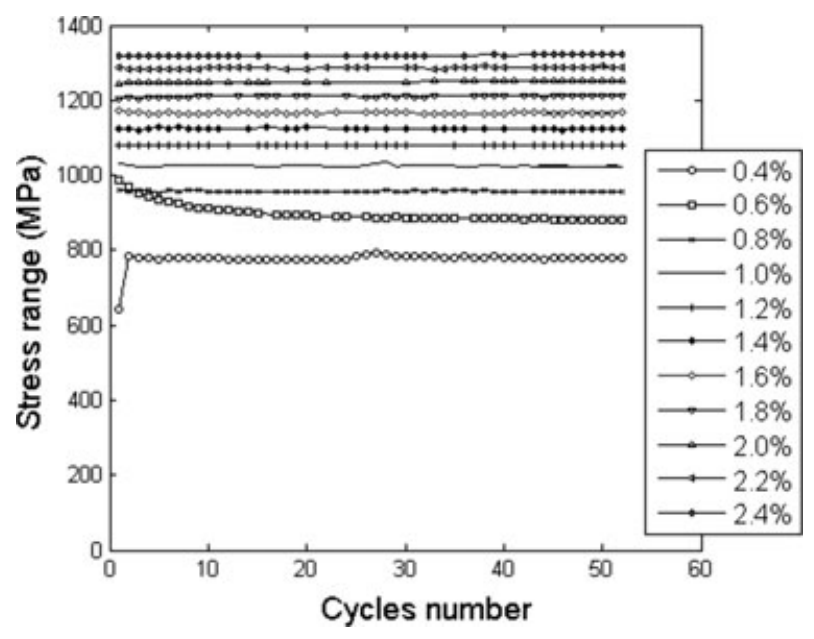

Fig. 5 Hardening/softening behaviour of the ER7 steel during strain-controlled tests, depending on the strain range level.

The hardening/softening behaviour, corresponding to the evolution of the cyclic stress versus the number of cycles, is plotted in Fig. 5 for the different strain ranges. A quasi-stabilized response of the material is obtained in the early cycles. The 50th cycle is then chosen as the stabilized cycle and the corresponding responses (stress versus strain) for each strain range are presented in Fig. 6. The constitutive law and the calibration of parameters will be based on these responses. HCF tests were also performed for the ER7 material under reversed tensile and reversed torsion loadings. The corresponding fatigue data are given in Table 2, where $\sigma_{w}$ : the fatigue limit in tension-compression and $\tau_{w}$ : the fatigue limit in alternate torsion.

Note here that the fatigue parameters obtained by Bernasconi et al..$^{16}$ for the ER7 material are slightly different $\left(\tau_{w}=289 \mathrm{MPa}, \sigma_{w}=340 \mathrm{MPa}, \tau_{w} / \sigma_{w}=0.85\right)$. It

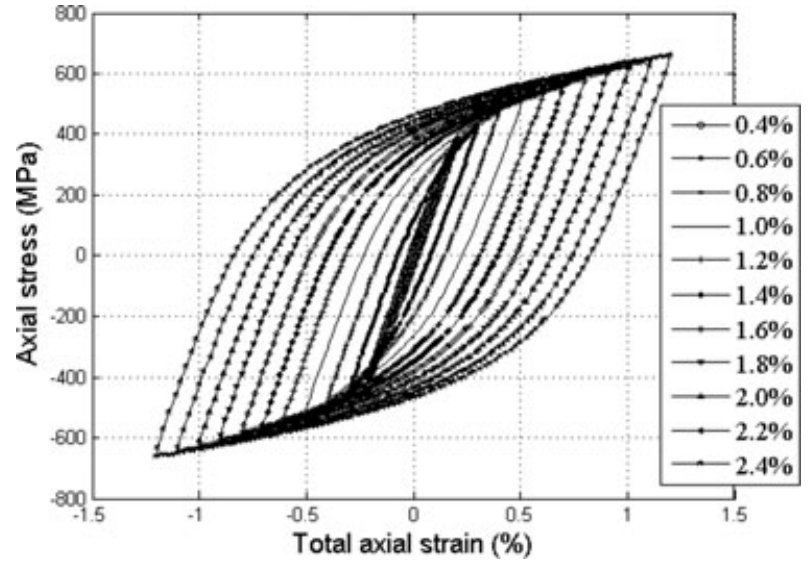

Fig. 6 Stabilized stress-strain curve for different strain ranges between 0.4 and $2.4 \%$

Table 2 Fatigue material parameters of ER7 steel

\begin{tabular}{lll}
\hline$\tau_{w}\left(M P_{a}\right)$ & $\sigma_{w}\left(M P_{a}\right)$ & $\left.\tau_{w} / \sigma_{w}\right)$ \\
\hline 353 & 435 & 0.81 \\
\hline
\end{tabular}

was shown that there is a slight anisotropy related to the position and direction of the specimen extraction..$^{21,22}$

\section{Constitutive law}

As an elastic-plastic behaviour is clearly observed in Fig. 6, the test results were interpreted using ArmstrongFrederick's ${ }^{23}$ nonlinear kinematic hardening plastic model presented under the following assumptions:

- Total strain decomposition: $\underline{\underline{\varepsilon}}^{=} \underline{\underline{\varepsilon}}_{e}+\underline{\underline{\varepsilon}}_{p}$

- Elastic strain: $\underline{\underline{\varepsilon}}_{e}=\frac{1+v}{E} \underline{\underline{\sigma}}-\frac{v}{E} \operatorname{Tr}(\underline{\underline{\sigma}}) \underline{\underline{I}}$

- Yield function: $f(\underline{\underline{\sigma}})=\mathcal{F}_{2}(\underline{\underline{\sigma}}-\underline{\underline{X}})-k$ with $\mathcal{f}_{2}(\underline{\underline{\sigma}}-\underline{\underline{X}})=\sqrt{\frac{3}{2}(\underline{\underline{S}}-\underline{\underline{X}}):(\underline{\underline{S}}-\underline{\underline{X}})}$ according to the von Mises criterion.

- Hardening law: $\underline{\underline{X}}=\frac{2}{3} H \underline{\underline{\dot{\varepsilon}}}_{p}-\gamma \underline{\underline{X}}_{p}$ and $\dot{p}=$ $\sqrt{\frac{2}{3} \dot{\underline{\varepsilon}}_{p}: \dot{\underline{\varepsilon}}_{p}}$,

where

$\underline{\underline{\varepsilon}}_{e}$ : the elastic strain tensor; $\underline{\underline{\varepsilon}}_{p}$ : the plastic strain tensor; $E$ : the Young modulus; $v$ : the Poisson ratio; $\underline{\underline{I}}$ : the second rank identity tensor; $k$ : the yield stress; $\mathcal{F}_{2}$ : the second invariant of deviatoric stress tensor; $\underline{\underline{S}}$ : the deviatoric stress tensor; $\underline{\underline{X}}$ : the backstress tensor; $\dot{p}$ : the cumulative plastic strain rate; and $H, \gamma$ : the hardening parameters of the Armstrong-Frederick constitutive law. It is well known that this model is not the best candidate when ratcheting occurs. ${ }^{24,25}$ However, as the objective is to have a first estimation of elastic or plastic shakedown 


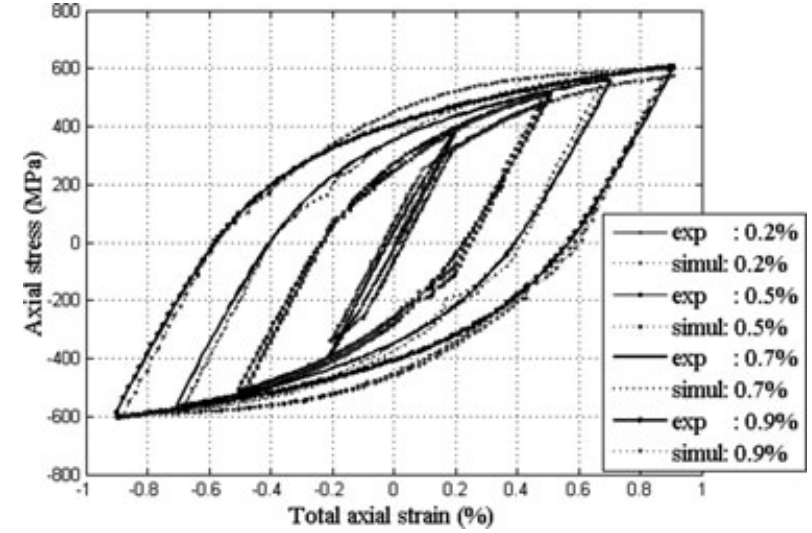

Fig. 7 Stabilized stress-strain curve: comparison between experimental and simulation values.

Table 3 Material parameters obtained by genetic algorithms

\begin{tabular}{llll}
\hline$E(M P a)$ & $k(M P a)$ & $H(M P a)$ & $\gamma$ \\
\hline 208550 & 296 & 128900 & 276 \\
\hline
\end{tabular}

and as the Armstrong-Frederick model is already available in Abaqus FE code, this model is chosen. Other models can be numerically implemented if necessary in order to have a better estimation of asymptotic regimes.

Test parameters have been identified using genetic algorithms, following Ref. [26]. In the present case, eight strain levels $\Delta \varepsilon / 2$ distributed between 0.2 and $0.9 \%$ are used to calculate the parameters.

The comparison between the experimental and the simulated stabilized stress-strain curves is presented in Fig. 7. One can observe a relatively good compromise for each strain range level. The materials parameters obtained are presented in Table 3.

In Fig. 8, the monotonic hardening curve and the cyclic curve, obtained experimentally and numerically are compared. It can be observed that the cyclic yield stress is lower than the monotonic stress. Similar results were obtained by Bernasconi et al..$^{21}$ This implies that considering cyclic data will increase the plastic strain obtained numerically, compared to monotonic data.

\section{NUMERICAL SIMULATION OF WHEEL/RAIL CONTACT}

\section{Model description}

The translation motion of the wheel with respect to the rail can be defined as the sliding between the two deformable bodies (the wheel and the rail) that are moving with different velocities. The equation of motion is then

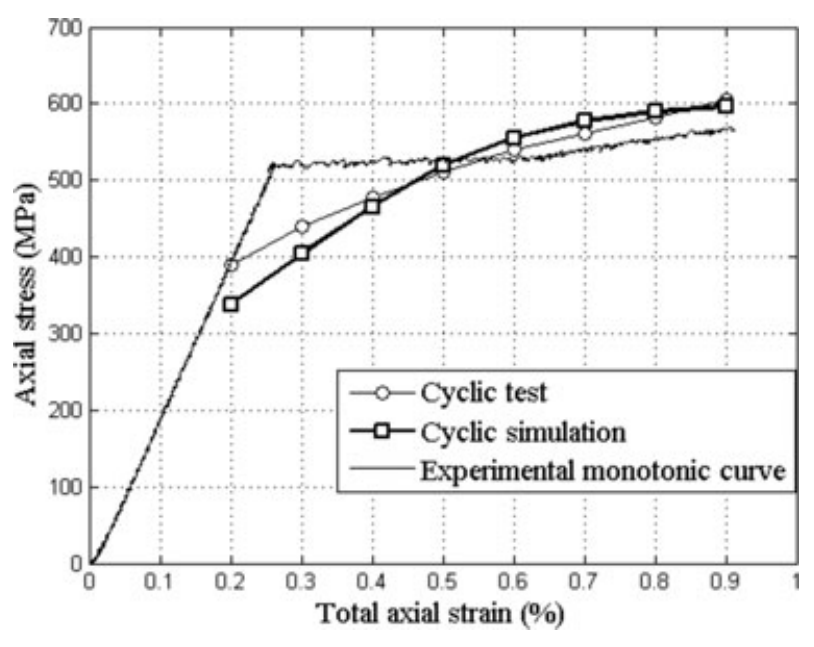

Fig. 8 Monotonic and cyclic material behaviour: comparison between simulation and experimental values.

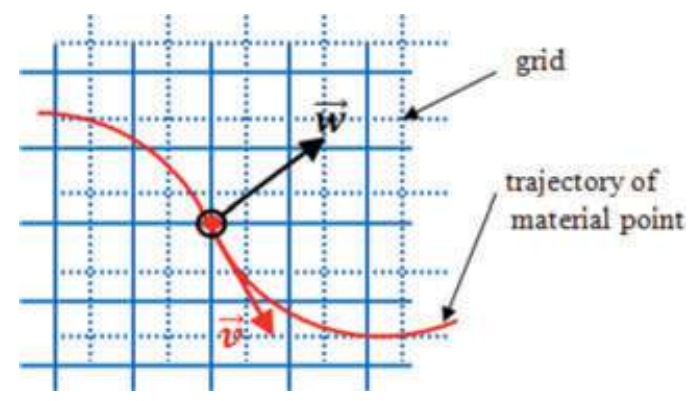

Fig. 9 Schematic representation of the equation of motion.

given by the equation of the particular derivative:

$\rho\left[\frac{\partial \vec{v}}{\partial t}+((\vec{w}-\vec{v}) \cdot \overrightarrow{\text { grad }}) \vec{v}\right]=\vec{f}+\operatorname{div} \vec{\sigma}$,

where $\vec{w}$ is the grid velocity, $\vec{v}$ : the material velocity, $\rho$ : the density, $\vec{f}$ : the volume loads, $\vec{\sigma}$ : the stress.

In this equation, when $w=v$, the Lagrangian formulation is obtained and when $w=0$, it corresponds to the Eulerian approach; this is illustrated in Fig. 9.

In the Lagrangian case, a very fine mesh has to be obtained over the entire wheel, which implies high CPU costs. This is the main reason that incremental $\mathrm{FE}$ computations of wheel/rail contact are difficult, which justifies a simplified approach as proposed by Ekberg et al., for example. ${ }^{1,5,12}$ In Eulerian case, a Eulerian-based steadystate method can be used to calculate the stabilized mechanical response of the wheel. The main advantage of this method is that the mesh has to be refined only in the contact zone, strongly reducing the computational cost. The steady-state transport analysis requires the definition of streamlines, which are the trajectories that the material follows during the transport through the mesh. 


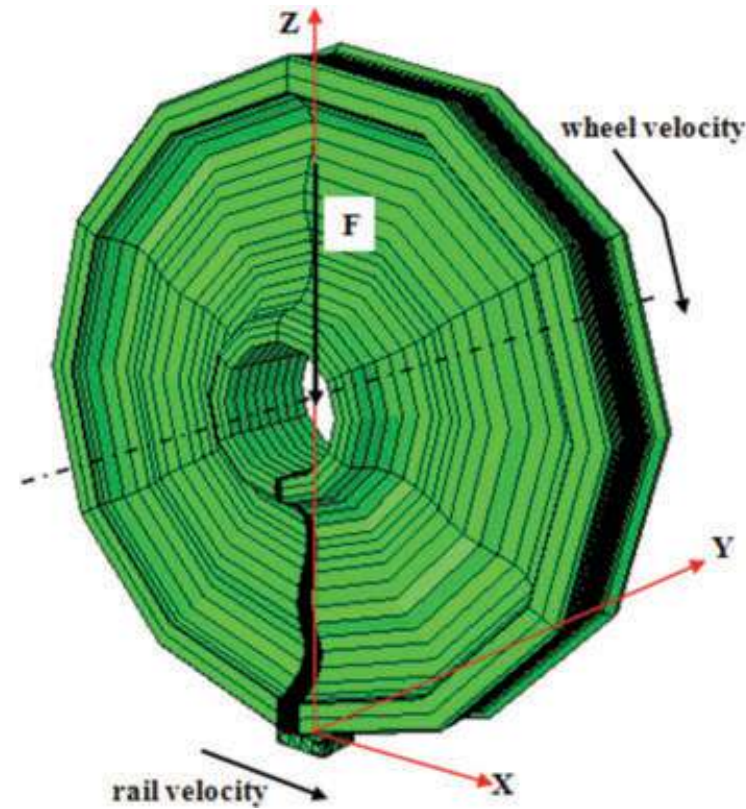

Fig. 10 3D FE model of wheel/rail contact.

In this study, the Abaqus/standard FE code has been used. The $3 \mathrm{D}$ model of the wheel/rail contact is created in two steps ${ }^{6,7}$ : firstly, an axisymmetric computation in $2 \mathrm{D}$ and then, after revolving the axisymmetric model of the wheel about its revolution axis, a complete 3D analysis using the steady-state algorithms implemented in Abaqus/standard. The axisymmetric model is meshed with 993 axisymmetric elements of the four-node bilinear CGAX4 type. The radius of the wheel is $457 \mathrm{~mm}$. The complete 3D wheel/rail model is meshed with 60884 elements (12-node cylindrical brick CCL12 for the wheel, four-node linear tetrahedron C3D4 for the rail; see Fig. 10). The element size in the contact area is $1 \mathrm{~mm}$.

Boundary conditions are as follows (see Fig. 10): the wheel hub is blocked along $\mathrm{x}$ and $\mathrm{y}$ and is free along $\mathrm{z}$; the rail is blocked along $\mathrm{x}, \mathrm{y}$ and $\mathrm{z}$ axis and normal load $F$ is applied to the wheel axis. The rotation is started with a constant running speed corresponding to a translational velocity of $160 \mathrm{~km} / \mathrm{h}$. An augmented Lagrangian formulation is used to solve the wheel/rail contact problem. This formulation is based on the Lagrangian multiplier and the penalty method. The friction coefficient has been introduced through the classical Coulomb friction law.

The steady-state method implemented in the Abaqus/standard FE code allows the introduction of a translational and angular velocity value for the wheel. The relative sliding is given by the following relation (Fig. 11):

$s=\frac{|V-R \omega|}{V^{\prime}}$ with $V^{\prime}=\frac{V+R \omega}{2}$
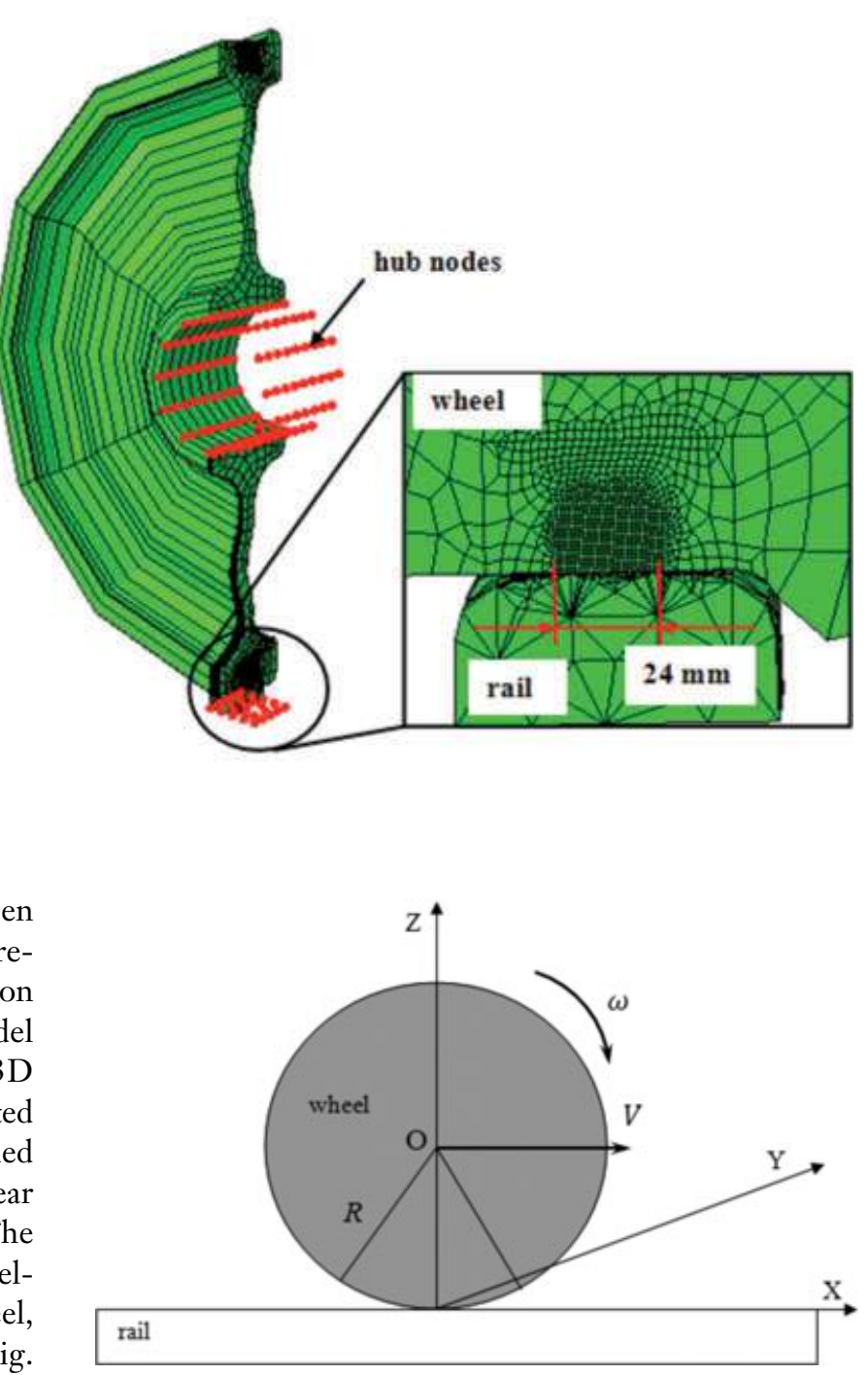

Fig. 11 Velocity definition.

$V$ : the translational velocity of the wheel, $\omega$ : the angular velocity of the wheel, $R$ : the radius of the wheel.

Several cases can be studied:

- If $s=0$ : pure rolling (no sliding)

- If $0<s<2$ : sliding

- If $=2$ : skating of the wheel; this is the extreme case where the angular velocity of the wheel is zero.

In the following, these three different cases will be studied.

\section{Results}

The rolling velocity is applied to the wheel. Two normal loads, $20 \mathrm{kN}$ and $50 \mathrm{kN}$, are applied on the axle of the 


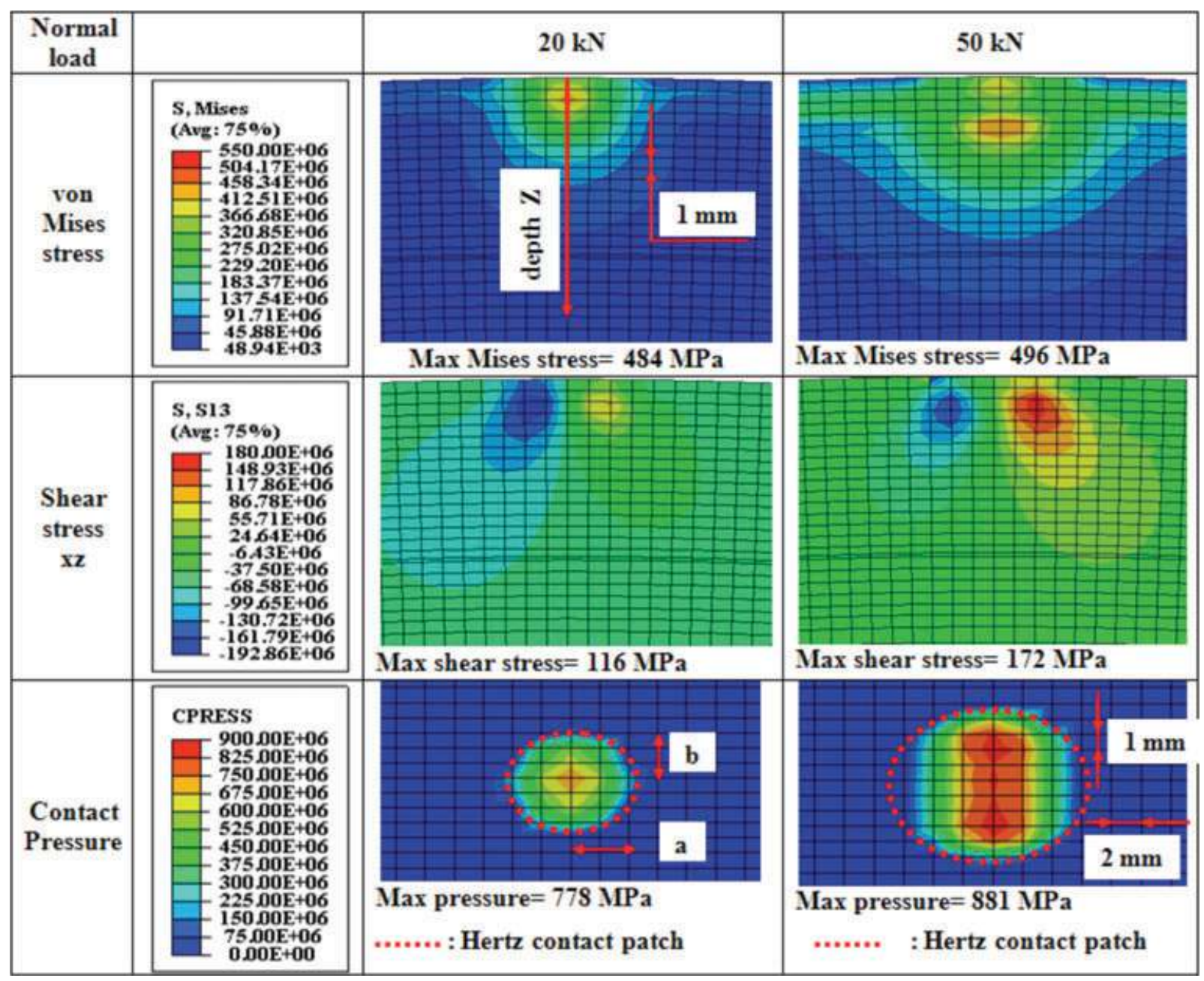

Fig. 12 Results of simulation in the wheel for two load levels and in pure rolling.

Table 4 Dimension of numerical contact patch and comparison with the Hertz theory

\begin{tabular}{lllll}
\hline & $a(\mathrm{~mm})$ & $b(\mathrm{~mm})$ & $z(\mathrm{~mm})$ & $P_{o}(\mathrm{MPa})$ \\
\hline Normal load & $20 \mathrm{kN}$ & & & \\
Hertz theory & 3.9 & 2.9 & 1.5 & 841 \\
Numerical results & 3.83 & 3.0 & 2 & 778 \\
Normal load & $50 \mathrm{kN}$ & & & \\
Hertz theory & 5.3 & 4.0 & 2.1 & 1142 \\
Numerical results & 4.83 & 5.0 & 3.99 & 881 \\
\hline
\end{tabular}

wheel. The friction coefficient is equal to 0.2 . The results are presented in Fig. 12 in terms of von Mises stress, shear stress (direction $\mathrm{xz}$ ) and contact pressure in pure rolling $(s=0)$.

It can be observed that the maximum von Mises and shear stresses values are located below the wheel tread and the corresponding contact patch is almost elliptic. The Table 4 compares the numerical results and Hertz elastic contact theory. It concerns the size of the contact patch ( $a$ and $b$ are the characteristic dimensions of the elliptic contact shape), the depth where the shear stress is maximal ( $\mathrm{z}$ is the depth at which the von Mises stress is maximum) and the maximal contact pressure $P_{0}$. A relatively good correlation with the Hertz theory can be observed for 20 $\mathrm{kN}$ for the contact patch. The results are slightly different for the depth at which the stress is maximum and the depth where the maximum pressure because the material is not purely elastic but at elastic shakedown. At $50 \mathrm{kN}$, the contact patch is crushed; this can be explained by the plastic deformation of the material for higher loadings.

In order to analyze the asymptotic response of the material, as an illustration, the local stress-strain response is obtained on a streamline located in the maximum shear stress area (Figs 13 \& 14). It can be seen that the load strongly influences the asymptotic response of the material. An elastic shakedown is obtained for $20 \mathrm{kN}$ and a plastic shakedown for $50 \mathrm{kN}$. The objective of this computation is to study the influence of the loads on the 


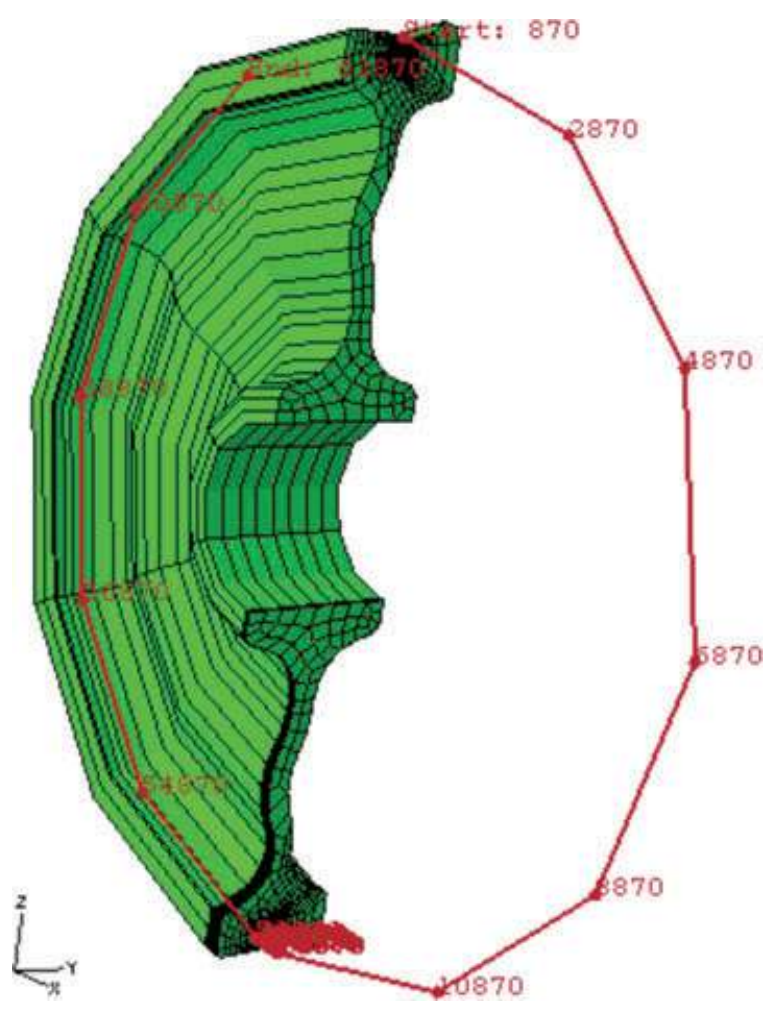

Fig. 13 Example of a streamline extracted from the wheel's 3D mesh.

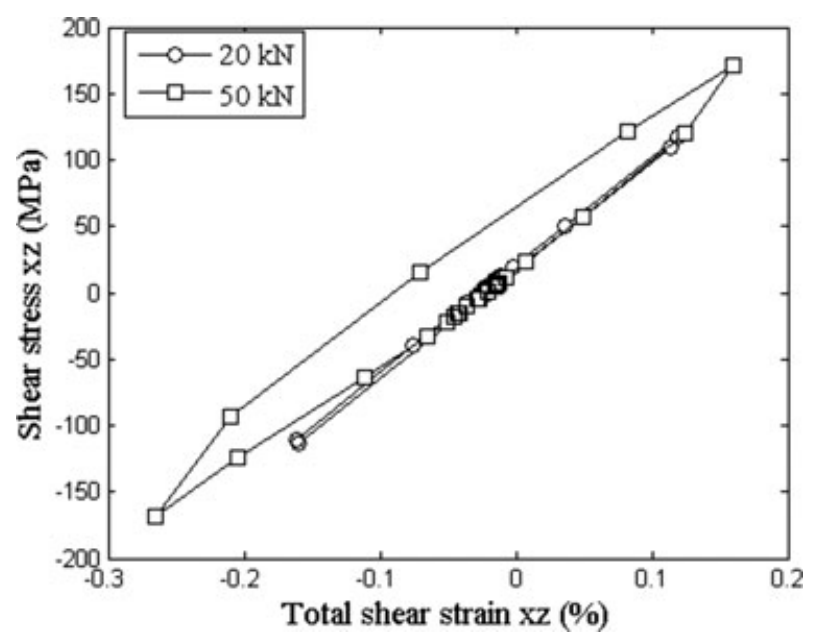

Fig. 14 Local stress-strain response at the maximum shear stress node: no sliding.

asymptotic response of the material. When elastic shakedown is obtained, HCF criteria can be applied. This is the case for a $20 \mathrm{kN}$ loading. When plastic shakedown occurs (50 kN loading), a low cycle fatigue (LCF) criterion can be applied. In this paper, only HCF criterion is used to perform a fatigue analysis as LCF tests are under progress.

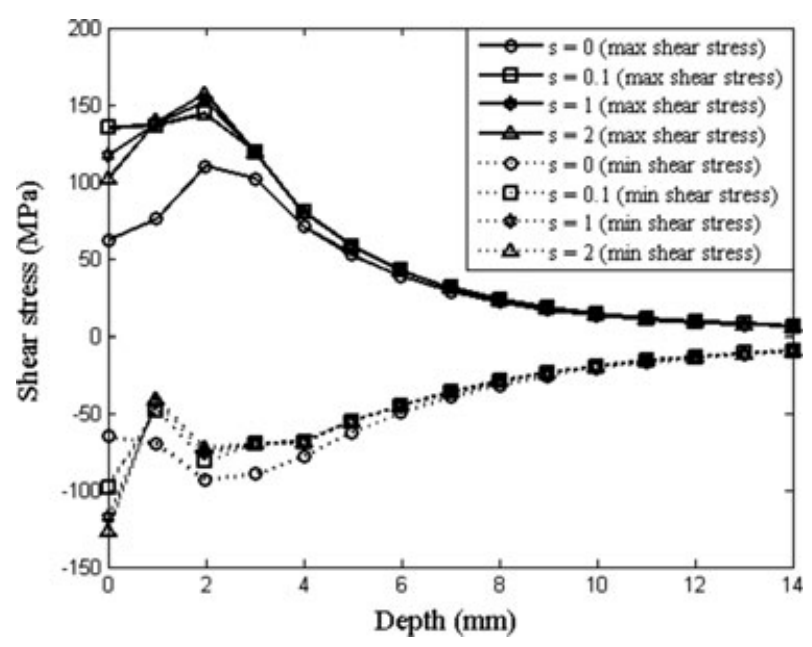

Fig. 15 Evolution of deep shear stress for different sliding coefficients.

\section{Influence of sliding on the material response and fatigue path}

\section{Asymptotic responses}

The aim of this part is to study the influence of sliding on the asymptotic response of the material. Figure 15 describes the evolution of the maximal and minimal shear stress versus depth for different sliding conditions. The normal load is equal to $20 \mathrm{kN}$. For $\mathrm{s}=0$ (pure rolling conditions) the maximal and minimal shear stress are located at the sub-surface in the contact; in sliding conditions the minimal value is located at the surface, but the maximum value is located at the sub-surface.

The maximum value of the shear stress is obtained deep for all the configurations. The local stabilized stress-strain loops obtained along the streamline of the maximal shear stress node for several values of sliding conditions are plotted in Fig. 16. It can be seen that the stress path is translated to positive values of shear strain due to the effect of the sliding.

\section{High cycle fatigue analysis}

In this study, only HCF is addressed and the Dang Van criterion ${ }^{13,27}$ is applied to determine the critical area. The Dang Van criterion is defined as a linear combination of the shear amplitude $\tau(t)$ and the hydrostatic pressure $P(t)$ as follows:

$\max _{\bar{n}}\left\{\max _{t}[\tau(\bar{n}, t)+\alpha P(t)] \leq \beta\right.$,

where $\bar{n}$ is the normal of shear plane, $\alpha$ is a material parameter representing the influence of the hydrostatic stress and $\beta$ is a material parameter representing the fatigue 


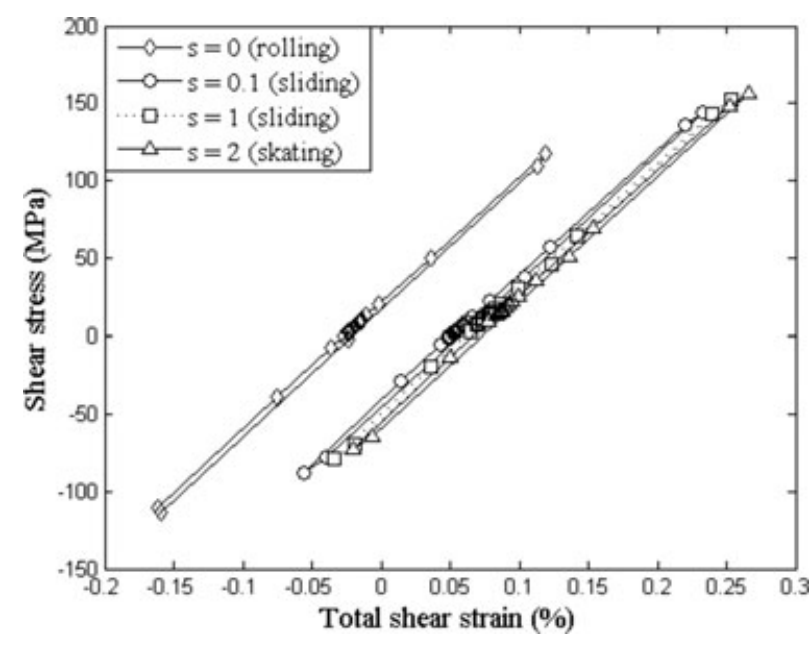

Fig. 16 Local stabilized shear stress-strain at the maximum shear stress node: $20 \mathrm{kN}$ loading.

limit in pure shear given by (see Table 2)

$\alpha=3\left(\frac{\tau_{w}}{\sigma_{w}}-\frac{1}{2}\right) \quad$ and $\quad \beta=\tau_{w}$.

At the stabilization state, the maximization on $\vec{n}$ provides the maximum mesoscopic shear stress given by

$\tau(t)=\max _{\bar{n}}[\tau(\bar{n}, t)]$.

The previous criterion is then written

$\max _{t}[\tau(t)+\alpha P(t)] \leq \beta$,

where $\tau(t)$ is calculated by defining the smallest hypersphere circumscribed to the loading path.

The fatigue path can be studied for different points located at the surface and sub-surface (see Fig. 17). Points 1 and 6 are located at the subsurface where the shear stress has its maximum value; Points 3 and 4 are located at the contact surface. Figure 18 shows the fatigue path suitable for these different points when there is no sliding. Point 1 is the node at which the shear stress is maximal; the risk of fatigue crack is maximal in Point 2. It can be explained by the effect of hydrostatic pressure plotted at the two points as it is shown in Fig. 19. The more the node is at the contact surface, the greater the hydrostatic pressure is. Concerning the fatigue path, similar results have been obtained by Dang Van et al. ${ }^{28}$ for the rail.

In Fig. 20 the influence of the sliding on the fatigue path plotted at the fatigue crack node can be observed. The fatigue damage risk is given by the minimal distance between the fatigue path to the Dang Van limit by the following relation:

$d_{\text {min }}=\frac{\left|\tau_{p}+\alpha P_{\max p}-\beta\right|}{\sqrt{1+\alpha^{2}}}$,

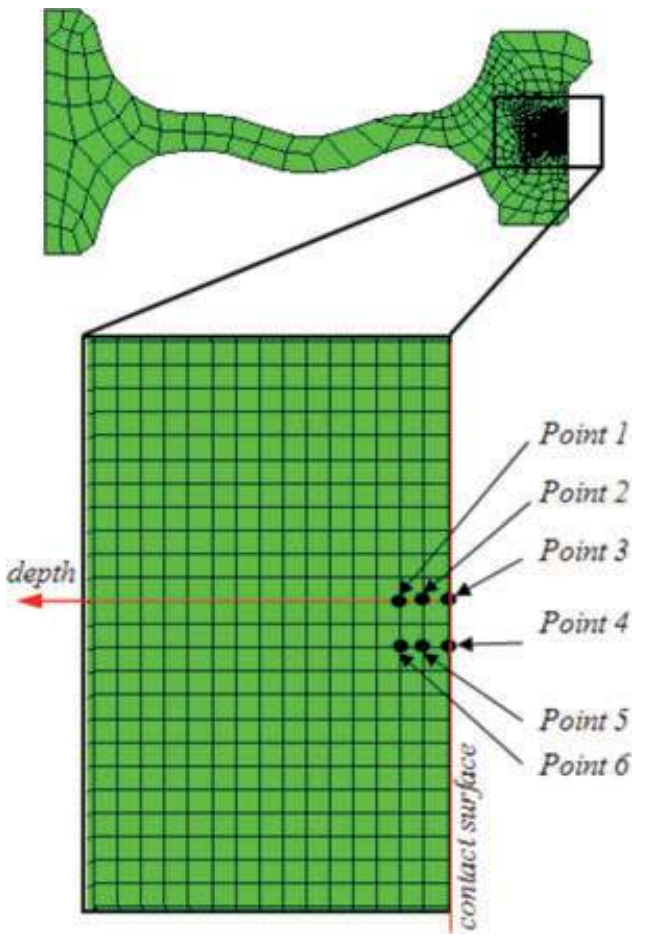

Fig. 17 Different points in the contact.

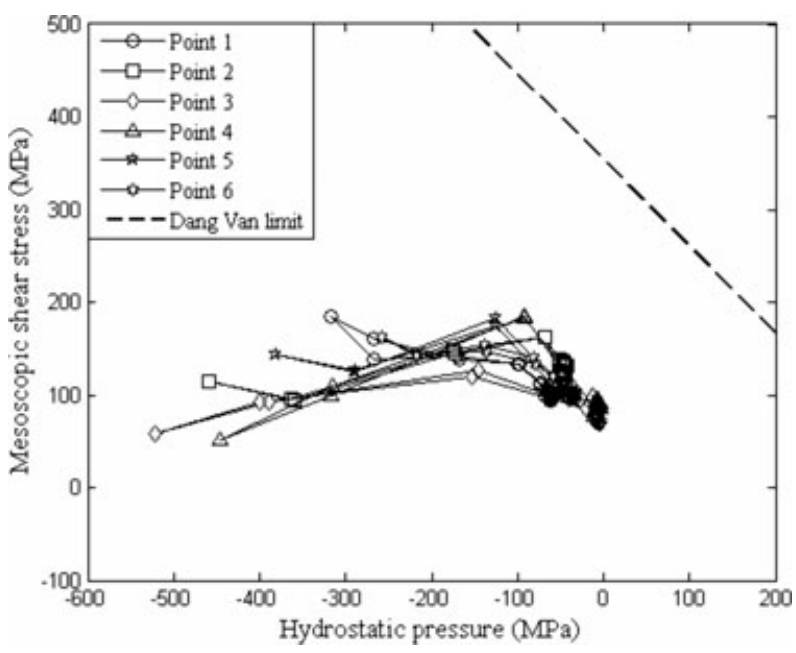

Fig. 18 High cycle fatigue prediction for the ER7 steel for $s=0$ at different points: $20 \mathrm{kN}$ loading.

where $\left(\tau_{p}, P_{\max p}\right)$ are the coordinates of the fatigue path. The lower the distance $d_{\min }$, the higher the risk of fatigue is. Then, it can be observed in Fig. 20 that the risk of cracking is the highest when sliding is present in the contact and the case of sliding $s=0.1$ is the most critical. It can be also observed that the shear stress level has increased.

The isovalues of the Dang Van fatigue criterion (minimal critical distance) have also been plotted in Fig. 21 on the section of the wheel for different cases of sliding. It can 


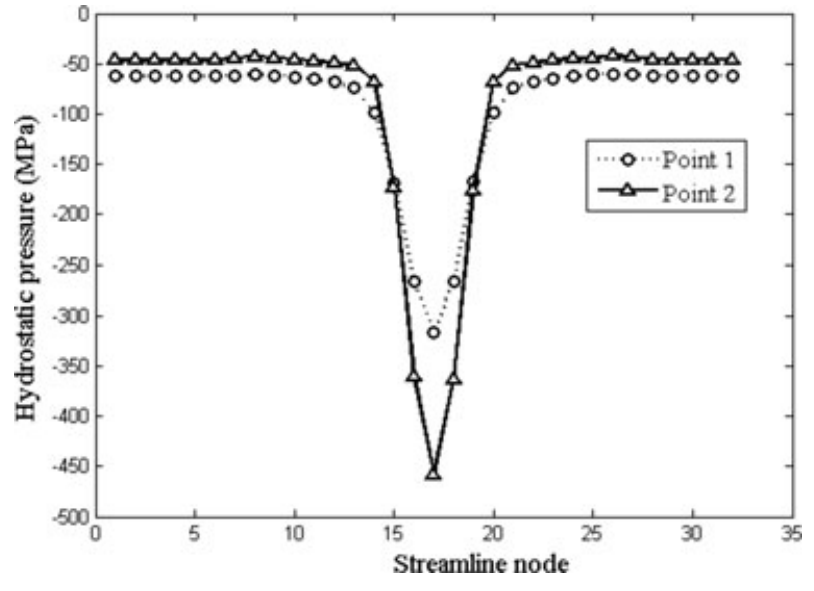

Fig. 19 Circumferential evolution of the hydrostatic pressure for $\mathrm{s}=0$ along streamlines of the node where shear stress is maximum and fatigue security is minimum: $20 \mathrm{kN}$ loading.

be observed that the risk of damage is more pronounced in the contact patch. Globally, the crack is located deep in pure rolling $(s=0)$, corresponding to Point 2, and at the surface in sliding $(s=0.1, s=1, s=2)$, corresponding to Point 4. One has to note that recently, it has been shown that Dang Van prediction could be non-conservative due to high compressive stresses and propositions have been done in order to correct this effect. ${ }^{14,29}$ This could improve the present results.

\section{CONCLUSION}

A methodology for analyzing of the risk for RCF of railway wheels taking into account the cyclic behaviour of

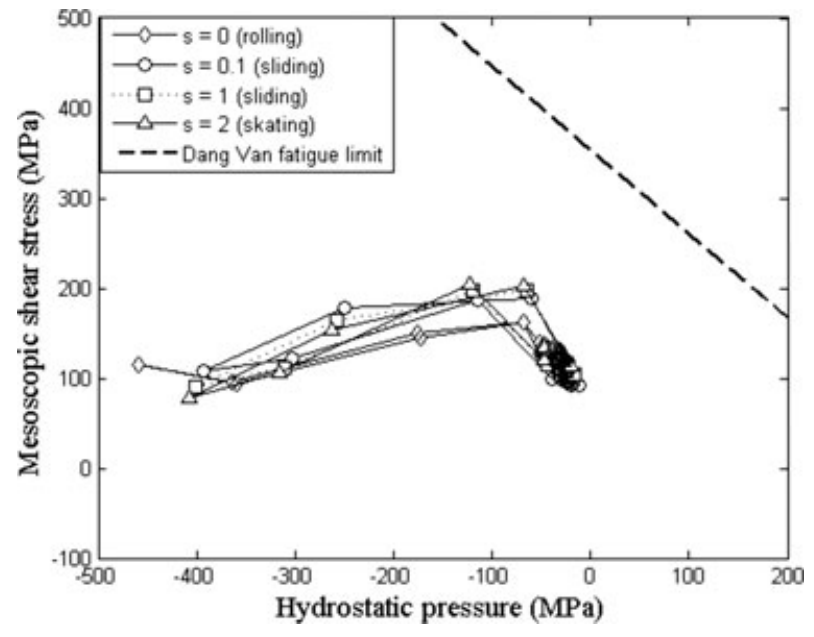

Fig. 20 Fatigue prediction for ER7 steel at the critical node for different sliding coefficients: $20 \mathrm{kN}$ loading.

material has been proposed. The different steps of this approach are the following: (1) choice of a cyclic mechanical constitutive law and identification of its associated parameters, (2) determination of the mechanical responses in the wheel based on the use of the steady-state method, and (3) choice and application of a fatigue criterion. In the first step, Armstrong Frederick's nonlinear kinematic hardening model was used to describe the mechanical behaviour of the material subjected to cyclic mechanical loadings. Genetic algorithms were used in order to determine the associated materials' parameters. The steady-state method based on the Eulerian approach is then used to determine local stress and strain responses.

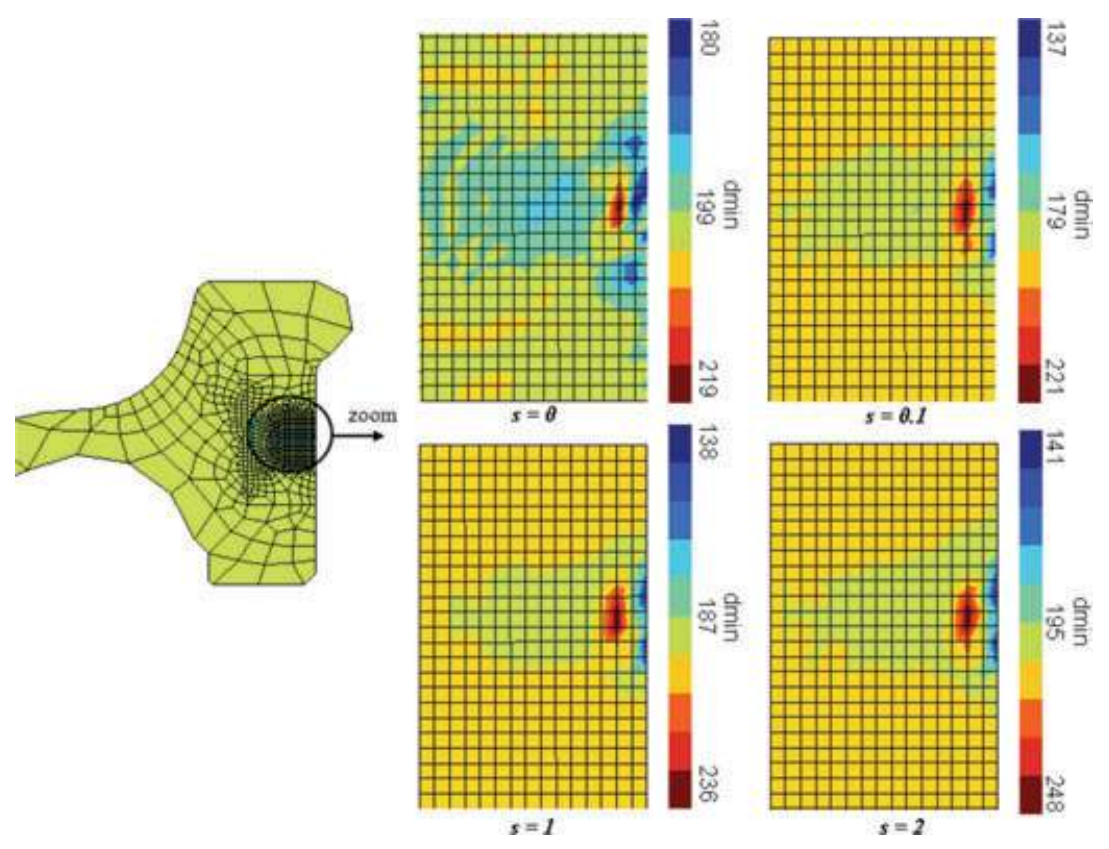

Fig. 21 Isovalues of Dang Van criterion for different sliding coefficients: $20 \mathrm{kN}$ loading. 
The changes in stress and strain fields can then be determined after each loading and analyzed using the Dang Van HCF criterion.

The results show that the node at which the shear stress is maximal is not the same as the node in which the risk of cracking is the greatest.

The effect of sliding on fatigue life has been studied and the results show that the case of rolling with sliding is more severe than without sliding. The case of sliding $s=0.1$ is the most critical. For the sliding conditions, the node at which the crack initiation is highest is located at the contact surface but for rolling conditions, it is below the wheel tread. LCF analysis will be the next step of this work, based on the works of Manson-Coffin, ${ }^{18,19}$ Ellyin and Golos, ${ }^{30} \mathrm{Koh},{ }^{31}$ and Amiable et al. ${ }^{32}$

\section{Acknowledgements}

The present research was supported by International Campus on Safety and Intermodality in Transportation, the Nord-Pas-de-Calais Region. The authors gratefully acknowledge the support of these institutions.

\section{REFERENCES}

1 Ekberg, A., Kabo, E. and Andersson, H. (2002) An engineering model for prediction of rolling contact fatigue of railway wheels. Fatigue Fract. Eng. Mater. Struct., 25, 899-909.

2 Johnson, K. L. (1985) Contact Mechanics. Cambridge University Press, Cambridge, UK, p. 452.

3 Hertz, H. (1882) Über die Berührung fester elastischer Körper. Fournal für reine und angewandte Mathematik, 92,156-171.

4 Kalker, J. J. (1990) Three-Dimensional Elastic Bodies in Rolling Contact. Kluwer Academic Publishers, Dordrecht, Netherland, p. 314.

5 Ekberg, A., Bjarnehed, H. and Lunden, R. (1995) A fatigue life model for general rolling contact with application to wheel/rail damage. Fatigue Fract. Eng. Mater. Struct., 18, 1189-1199.

6 Langueh, A., Brunel, J.-F., Charkaluk, E., Dufrénoy, P. and Demilly, F. (2011) Influence of the steel grades on rolling contact fatigue of railway wheels. ICM11, Proced. Eng., 10, 2627-2632.

7 Brunel, J.-F., Charkaluk, E., Dufrénoy, P. and Demilly, F. (2010) Rolling contact fatigue of railways wheels: influence of steel grade and sliding conditions. Proced. Eng., 2, 2161-2169.

8 Johnson, K. L. and Jefferis, J. A. (1963) Plastic flow and residual stresses in rolling and sliding contact. In: Proc. Symp. on Fatigue in Rolling Contact, Institution of Mechanical Engineers, London, pp. 50, 207-290.

9 Johnson, K. L. (1962) A shakedown limit in rolling contact. In: ASME Proc. 4th National Conference of Applied Mechanics, Berkley, pp. 971-975.

10 Ekberg, A. and Sotkovszki, P. (2001) Anisotropy and rolling contact fatigue of railway wheels. Int. F. Fatigue, 23, 29-43.

11 Ekberg, A. (1997) Rolling contact fatigue of railway wheels- a parametric study. Wear, 211, 280-288.
12 Ekberg, A. (1996) Rolling contact fatigue of railway wheels-computer modeling and in-field data. In: Proceedings of the Second Mini Conference on Contact Mechanics and Wear of Rail/Wheel Systems. Budapest, pp. 154-163.

13 Dang Van, K., Griveau, B. and Message, O. (1989) On a new multiaxial fatigue limit criterion: Theory and application. In: Biaxial and Multiaxial Fatigue, Mechanical Engineering Publications, London, pp. 479-496.

14 Desimone, H., Bernasconi, A. and Beretta, S. (2006) On the application of Dang Van criterion to rolling contact fatigue. Wear, 206, 567-572.

15 Bernasconi, A., Davoli, P., Filippini, M. and Foletti, S. (2005) An integrated approach to rolling contact sub-surface fatigue assessment of railway wheels. Wear, 258, 973-980.

16 Bernasconi, A., Filippini, M., Foletti, S. and Vaudo, D. (2006) Multiaxial fatigue of a railway wheel steel under non proportional loading. Int. F. Fatigue 28, 663-72.

17 Dang Van, K. and Maitournam, M. H. (2002) On some recent trends in modeling of contact fatigue and wear in rail. Wear, 253, 219-227.

18 Manson, S. S. (1965) Fatigue: a complex subject - some simple approximation. Exp. Mech., 5, 193-226.

19 Coffin, L. F. (1954) A study of the effect of cyclic thermal stresses on a ductile metal. Trans. ASME, 76, 931-50.

20 AFNOR, NF EN 13262 (2004) October.

21 Bernasconi, A., Davoli, P. and Filippini, M. (2001) Fatigue life of railway wheels: residual stresses and LCF. In: Proceeding of the 13th International Wheelest Congress, Rome.

22 Ekberg, A. and Sotkovszki, P. (2001) Anisotropy and rolling contact fatigue of railway wheels. Int. F. Fatigue 23, 29-43.

23 Armstrong, P. J. and Frederick, C. O. (1966) Technical Report $R D / B / N 731$, Berkeley Nuclear Laboratories.

24 Jiang, Y. and Sehitoglu, H. (1999) A model for rolling contact failure. Wear, 224, 38-49.

25 Portier, L., Calloch, S., Marquis, D. and Geyer, P. (2000) Ratchetting under tension-torsion loadings: experiments and modeling. Int. F. Plast., 16, 303-335.

26 Andrade-Campos, A., Thuillier, S., Pilvin, P. and Teixeira-Dias, F. (2007) On the determination of material parameters for internal variable thermoelastic-viscoplastic constitutive models. Int. F. Plast., 23, 1349-1379.

27 Dang Van, K. (1993) Macro-micro approach in high-cycle multiaxial fatigue. In: Adavances in multiaxial fatigue, ASTM STP 1991 (Edited by D. L. McDowell and R. Ellis), American Society for Testing and Materials, Philadelphia, pp. 120-130.

28 Dang Van, K., Maitournam, M. H. and Prasil, P. (1996) Elastoplastic analysis of repeated moving contact: application to railways damage phenomena, Wear, 196, 77-81.

29 Houpert, L. and Chevalier, F. (2012) Rolling bearing stress based life - Part 1: Calculation model. F. Tribol., 134, 021103.1-021103.13.

30 Ellyin, F. and Golos, K. (1988) Multiaxial fatigue damage criterion. 7. Eng. Mater. Technol., 110, 63-68.

31 Koh, S. K. (2002) Fatigue damage evaluation of a high pressure tube steel using cyclic strain energy density. Int. 7 . Press. Vess. Piping, 79, 791-798.

32 Amiable, S., Chapuliot, S., Constantinescu, A., and Fissolo, A. (2006) A computational lifetime prediction of a thermal shock experiment. part II: discussion on different fatigue criteria. Fat. Frac. Eng. Mater. Struct., 29, 219-227. 